\title{
Discursos sobre a surdez no Portal do Professor do MEC: desnaturalizando estereótipos e essencializações
}

\author{
Discourses about deafness on the Teacher Portal of the MEC: \\ deconstructing stereotypes and essentializations
Los discursos sobre la sordera en el Portal del Maestro MEC: desnaturalizado estereotipos y essentializations

\author{
Ana Flávia Teodoro de Mendonça Oliveira ${ }^{1}{ }^{1}$ \\ Clarissa Martins de AraúJo ${ }^{2}{ }^{2}$ \\ ${ }^{1}$ Universidade Federal de Goiás, Goiânia, GO, Brasil. \\ ${ }^{2}$ Universidade Federal de Pernambuco, Recife, PE, Brasil.
}

\begin{abstract}
RESUMO
O artigo analisa a representação cultural da surdez nos discursos midiáticos do Portal do Professor do Ministério da Educação (MEC). Este estudo busca, então, identificar os estereótipos e as possíveis essencializações existentes na produção dos docentes. Com base na perspectiva foucaultiana de análise arqueológica do discurso, foram selecionados como arquivo documentos produzidos no "Jornal do Professor", nos "Vídeos Institucionais" e no "Espaço da aula". Os resultados revelam que, apesar da heterogeneidade de técnicas subsidiadas pelo Portal, os discursos produzem a surdez de maneira pejorativa e estereotipada, através de terminologias como "falta/limitação", "mudez/silêncio", "deficiência auditiva"; enfatizam também o uso da Libras como condição para inclusão. Podemos inferir, portanto, que a representação da surdez nesses discursos continua presa à concepção clínica da deficiência, o que reforça os mitos comuns sobre os surdos. Desse modo, os professores em formação parecem representá-los como sujeitos que possuem identidade fixa, estável, estática e permanente.
\end{abstract}

Palavras-chave: Surdez. Representação Cultural. Estereótipo.

\begin{abstract}
This article analyzes the cultural representation of deafness in mediatic discourses of the Teacher Portal of the Ministry of Education (MEC), seeking to identify the stereotypes and the possible essentializations which happen through the production of teachers. Our analysis is based on Foucault's perspective of archaeological discourse analysis. As the file a set of documents were available in the Teacher's Journal, in Institutional videos and in the Classroom. The results show that, despite the heterogeneity of techniques subsidized by the Portal, persists a production of deafness in a pejorative and stereotyped way, through terminologies such as lack/limitation, muteness/ silence, hearing deficiency; they also emphasize the use of Libras as a condition for inclusion. We can infer that the representation of deafness in these discourses is still imprisoned by the clinical conception of deficiency, which reinforces common myths about the deaf. Teachers in the process of their own learning seem to represent them as subjects who possess a fixed, stable, static and permanent identity.
\end{abstract}

Keywords: Deafness. Cultural representation. Stereotype.

\section{RESUMEN}

El artículo analiza la representación cultural de la sordera en los discursos mediáticos del Portal del Profesor del Ministerio de la Educación (MEC) buscando identificar los esteriotipos y las posibles esencializaciones existentes en la producción de docentes. Nuestro análisis se basa en la perspectiva de Foucault del análisis del discurso arqueológico. Seleccionamos como archivo los documentos producidos en el Diario del Maestro, los Videos institucionales y en la Sala de Clases. A pesar de la heterogeneidad de las técnicas respaldadas por el Portal, los discursos producen sordera en forma despectiva y estereotipada a través de terminologías como falta/limitación, mudez/silencio, discapacidad auditiva; también destacan el uso de Libras como condición para la inclusión. Podemos deducir, que la representación de la sordera en esos discursos está unida a la concepción clínica de la discapacidad, lo que refuerza los mitos más comunes acerca de los sordos. De esta manera, los profesores en formación parecen representarlos como sujetos que tienen identidad fija, estable, estática y permanente.

Palabras clave: Sordera. Representación cultural. Esteriotipo. 


\section{INTRODUÇÃo}

Muitas pesquisas vêm evidenciando a necessidade da formação de professores para a educação inclusiva. Estudos realizados por Carvalho (1998), García (1999), Martins (2003), Mantoan (2005), entre outros, demonstram que, para que a inclusão se concretize, na plenitude de sua proposta, é necessário pensar na formação do professor. Como aponta Carvalho (1998), sem que haja uma formação dos educadores, corre-se o risco de apenas inserir a pessoa com deficiência no convívio com outros alunos, o que acaba promovendo uma forma de "inclusão excludente".

A partir dessa necessidade, a formação para a inclusão está se expandindo para outros espaços, como a internet. Nesse ambiente, um espaço formativo que nos chamou atenção foi o Portal do Professor do $\mathrm{MEC}^{1}$. Constatamos que muitos dos nossos alunos do curso de Pedagogia utilizavam-no para construir conhecimentos acerca da educação das pessoas com deficiência. Enquanto uns acessavam o portal para ter acesso a conteúdos multimídia sobre a deficiência, outros utilizavam essa plataforma na busca de auxílio para o planejamento de suas aulas e de materiais didático-pedagógicos produzidos nesse ambiente, sobretudo aqueles relacionados com às pessoas com deficiência.

No que se refere à representação da surdez na mídia, a pesquisa de Thoma (2002), por exemplo, investiga a alteridade surda e como ela é narrada, produzida, inventada, incluída ou excluída em filmes que abordam o tema da surdez. Afora isso, analisa os modos interpelativos de um grupo de sujeitos surdos universitários. Nas discussões dos resultados, a autora verifica a incidência pejorativa dos discursos cinematográficos quanto àqueles sujeitos. Na maioria dos casos, os indivíduos surdos são considerados incapazes, incorrigíveis, anormais, ignorantes e, até mesmo, primitivos. Além disso, o estudo de Thoma também retrata situações em que os surdos, apesar da deficiência, são recompensados por outros sentidos, o que os tornam, em contraponto à visão anterior, capazes, corrigíveis, normalizáveis, inteligentes, civilizados.

Já o estudo de Silva (2010), intitulado "Movimentos identitários e políticas de inclusão na mídia: a (d)eficiência em tela", objetiva compreender a forma com que a governamentalidade - inscrita nas práticas discursivas da mídia televisiva e nas relações entre saber-poder e verdade - possibilita o funcionamento da normalização do deficiente como resistência à exclusão.

\footnotetext{
${ }_{1}$ Ministério da Educação do Brasil. Portal do Professor do Brasil. Disponível em: http://portaldoprofessor.mec.gov.br/index.html. Acesso em: 14 dez. 2012
}

A autora levanta um amplo quadro representativo de materialidades midiáticas, veiculadas tanto na mídia impressa quanto na televisiva, entre 2003 e 2009, com o fim de demonstrar os mecanismos e as estratégias linguístico-discursivas empregadas para a produção de sentidos nessas materialidades que compõem o corpus da pesquisa.

Tais investigações apontam os diferentes sentidos e significados atribuídos à deficiência em artefatos culturais midiáticos distintos, a saber: livros, revistas, televisão, cinema, histórias em quadrinhos (HQs), entre outros. Os estudos evidenciam que, normalmente, as imagens e representações atribuídas pela cultura à pessoa com deficiência não têm sido positivas. Por nossa parte, preocupamo-nos eminentemente com os discursos emergentes dos artefatos culturais midiáticos destinados à formação de professores para educação inclusiva.

O leitor poderia, então, indagar por que motivos elegemos os discursos especificamente sobre a pessoa surda em uma formação docente on-line como enfoque analítico?

Além das razões já explicitadas, ou seja, a utilização da internet pelos graduandos de pedagogia como forma de apropriação de "saberes e fazeres" sobre a pessoa com deficiência e a contribuição/indagações de estudos nesse campo do conhecimento, consideramos que o Portal do Professor do MEC, como local de formação docente e, portanto, de produção discursiva sociopolítica, em suas formas peculiares de realização (recursos multimídia e digitais), transita e negocia significados sobre a pessoa com surdez. Nesse sentido, os discursos direcionados aos professores referentes a esse tema não podem ser considerados comuns, banais ou apenas puras terminologias.

Esse portal é um espaço formativo permanente que busca apoiar os cursos de capacitação do ProInfo Integrado ${ }^{2}$ a fim de atender não apenas aos professores que participam desses cursos, mas a todos que consultam esse espaço. Ele possui seis grandes áreas: Recursos Educacionais; Espaço da Aula; Jornal do Professor; Área de Cursos; Materiais; e Links. Cada área apresenta recursos de multimídia que atendem às suas especificidades, bem como espaços onde os professores podem apresentar sugestões e trocar experiências com colegas de outras regiões do Brasil. A plataforma tem ainda um jornal eletrônico onde publica eventos e reflexões de profissionais

\footnotetext{
${ }_{2}$ O ProInfo Integrado é um programa de formação voltado para o uso didático-pedagógico das Tecnologias da Informação e Comunicação (TIC) no cotidiano escolar. É articulado à distribuição dos equipamentos tecnológicos nas escolas e à oferta de conteúdos e recursos multimídia e digitais oferecidos pelo Portal do Professor, pela TV Escola e DVD Escola, pelo Domínio Público e pelo Banco Internacional de Objetos Educacionais.
} 
acerca do cotidiano escolar, além de uma revista eletrônica na qual os professores podem divulgar as opiniões e experiências em educação (BIELSCHOWSKY; PRATA, 2010).

Em muitas áreas do portal, existe uma atenção especial à educação dos surdos, pois estão presentes diversos conteúdos sobre a surdez. Esse aspecto nos leva a inferir que a plataforma, além de assumir um lugar importante na produção de "verdades" sobre as pessoas surdas, também atua instituindo práticas e definindo decisões pedagógicas de muitos professores.

Assim, ao nos fundamentarmos nos Estudos Culturais de vertente pós-estruturalista, entendemos que "os modos de dizer" sobre a surdez nos processos formativos docentes são práticas culturais cuja permanência deve ser inquirida, já que esses discursos ensinam ao professor o que é ser "surdo". Nessa direção, pretendemos examinar alguns dos discursos do Portal do Professor do MEC que tratam especificamente da surdez e que são veiculados através dos diversos artefatos culturais midiáticos disponibilizados ao professor por meio do "Jornal do Professor", dos "Vídeos Institucionais" e das aulas oferecidas no "Espaço da Aula". Dessa forma, objetivamos investigar a representação cultural da surdez nos discursos midiáticos do Portal do Professor do MEC, buscando identificar os estereótipos existentes na produção desses sujeitos.

Faz-se necessário destacar que concebemos representação cultural de acordo com a abordagem construcionista de Hall (1997, p. 28), em que "a representação é a produção de significados através da linguagem". Nessa perspectiva, a representação cultural é entendida como

[...] o processo pelo qual os membros de uma cultura utilizam a língua (amplamente definida como qualquer sistema que empregue signos, qualquer sistema significante) para produzir significados. Esta definição já carrega a importante premissa de que as coisas objetos, pessoas, eventos do mundo - não têm em si qualquer significado estabelecido, final ou verdadeiro. Somos nós - na sociedade, nas culturas humanas que fazemos as coisas significarem, que significamos (HALL, 1997, p. 61).

Logo, ao examinar os textos culturais do referido espaço formativo, interessamo-nos em saber se os enunciados que orientam, aconselham e instituem uma forma de atuação docente fundamentam-se em uma visão estereotipada da surdez. Bhabha (1998) afirma que estereótipo é uma forma de conhecimento e identificação que vacila entre o que está sempre no lugar, já conhecido, e algo que deve ser exaustivamente repetido. $\mathrm{O}$ autor enfatiza ainda que
[...] o estereótipo não é uma simplificação porque é uma falsa representação de uma dada realidade. É uma simplificação porque é uma forma presa, fixa, de representação que, ao negar o jogo da diferença (que a negação através do Outro permite), constitui um problema para a representação do sujeito em significações de relações psíquicas e sociais (BHABHA, 1998, p. 117).

Com efeito, acreditamos que, ao desvelar a representação cultural da surdez, podemos contribuir para a ruptura de certezas, de verdades e de crenças preestabelecidas a respeito dos sujeitos surdos, visando à problematização dos discursos formativos na área da educação inclusiva.

\section{Percurso teórico-metodológico}

A análise dos dizeres que produzem a surdez na trama discursiva do Portal do Professor do MEC foi realizada com base nos fundamentos da análise arqueológica de Foucault (2013). Sobre essa abordagem, consideramos pertinente apresentar algumas de suas características que nortearam o nosso olhar na etapa de investigação dos dados, a saber:
A arqueologia busca definir não os pensamentos, as representações, as imagens, os temas obsessões que se ocultam ou se manifestam nos discursos, mas os próprios discursos, enquanto práticas que obedecem a regras. [...] Não é o retorno ao próprio segredo da origem; é a descrição sistemática de um discurso- objeto (FOUCAULT, 2013, p. 169-170).

Nesse sentido, ao adotarmos essa abordagem como instrumento de análise, queremos salientar que não construímos um corpus de pesquisa, mas sim um arquivo. O arquivo, para Foucault (2013, p. 158), seria a lei "do que pode ser dito, o sistema que rege o aparecimento dos enunciados como acontecimentos singulares".

Selecionamos para o nosso arquivo de pesquisa textos culturais diversos sobre o surdo no Portal do Professor do MEC, uma vez que, ao examinar esse material, constatamos que as pessoas surdas se encontram na posição de serem narradas pelos outros, fazendo com que, na maioria dos registros, a voz deles seja silenciada. Quando dizemos que a pessoa surda tem um lugar de enunciação secundário nas materialidades analisadas, queremos esclarecer que suas enunciações não são reconhecidas, levando-nos a depreender que os processos discursivos presentes nos "Vídeos Institucionais", nas matérias veiculadas no "Jornal do Professor" e nos discursos das aulas ("Espaço da Aula"), destinados a formar o professor, silenciam o surdo enquanto sujeito e o fazem significar enquanto objeto. 


\section{OS DISCURSOS SOBRE A SURDEZ NA ESFERA DISCURSIVA DO PORTAL DO PROFESSOR DO MEC: DESCRIÇÃO DA}

Para discutir a produção cultural da surdez no portal investigado, apresentamos, inicialmente, uma análise do lugar de enunciação da deficiência. Nesse sentido, cabe esclarecer que os lugares de enunciação são instituições que reconhecem tanto os autores quanto os discursos produzidos por estes; é também o lugar em que se estabelecem as regras para a pronunciação do discurso.

É preciso destacar que o referido espaço formativo, enquanto instituição destinada à capacitação docente através das TICs, detém o seu estatuto de enunciador privilegiado no âmbito da educação por estar diretamente vinculado ao Ministério da Educação.

Nesse contexto, é importante registrar as formas de poder-saber na função enunciativa do referido portal, uma vez que, como instituição enunciadora, é conferida a esse espaço a legitimidade do saber intelectual e do saber científico por meio das inúmeras parcerias estabelecidas com universidades públicas nacionais e internacionais. Sobre isso, os dados disponibilizados no portal revelam que:

Para alcançar os conteúdos pesquisados na internet, constituímos uma parceria com as universidades federais do Ceará, de São Carlos, do Rio de Janeiro, de Minas Gerais, do Rio Grande do Sul, a Federal Fluminense, a UNB e a UNESPE de Presidente Prudente [...]. São estabelecidos acordos de colaboração entre instituições como as Universidades do Colorado, Califórnia e Utah (USA), Universidade de Alicante (Espanha), Instituto de Tecnologia da Califórnia (USA), dentre tantos outros (BIELSCHOWSKY; PRATA, 2010).

Além das parcerias com essas universidades, o portal recebe também a colaboração de entidades financeiras internacionais como a Organização das Nações Unidas para a Educação, Ciência e Cultura (UNESCO) e de algumas instituições nacionais privadas e públicas, tais como "Fundação Telefônica (Educarede), Bradesco, Vivo, Oi Futuro, Claro, OEI, Cezar, Instituto Algar e empresas como Intel, Corel, Cisco, Adobe, Microsoft, Agência Espacial Brasileira, Embrapa" (BIELSCHOWSKY; PRATA, 2010). O comprometimento ou a articulação do portal com esse conjunto de forças discursivas, advindas de lugares heterogêneos, demonstra que os discursos sobre a surdez que circulam nesse espaço formativo estão abertos a diferentes autorias e a afiliações diversas.

Assim, no "Jornal do Professor", nas aulas do "Espaço da Aula" e nos "Vídeos Institucionais" que integram os conteúdos multimídia, observamos que a surdez foi narrada por docentes formados em diferentes áreas; por profissionais que atuam na escola, como diretores e coordenadores pedagógicos; por profissionais ligados à gerência da Educação Especial; e também por especialistas, como fonoaudiólogos, psicopedagogos, fisioterapeutas e médicos.

É interessante constatar que os enunciados sobre a deficiência, embora estejam em textos predominantemente constituídos pelo discurso educacional, o sujeito discursivo na "ordem do discurso" apaga o saber escolar e evidencia o saber médico, de forma a caracterizar a deficiência. Assim, parece-nos que os discursos que orientam os professores, articulam-se com todo um aparato conceitual advindo de um saber médico, constituindo a ideia de surdez intimamente relacionada ao biológico, como podemos ver no excerto abaixo no Quadro 1:

Quadro 1 - Aula "Deficiência auditiva - entendendo como se formam os sons e como os captamos"

Atividade 1 - Em seguida, o professor deverá pedir para que os alunos assistam ao vídeo "Audição - Aparelho auditivo" [....]. O vídeo versa sobre as características e a importância do aparelho auditivo.

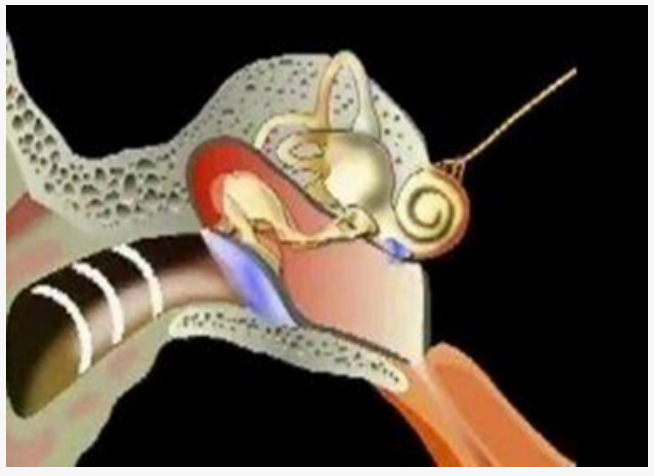

Atividade 2 - Nesta etapa, sugerimos que o professor organize os alunos em grupos de quatro integrantes - junção de duas duplas, para que discutam e respondam algumas questões, conforme roteiro abaixo, sobre o conteúdo no vídeo "Audição - Aparelho Auditivo"

Fonte: ANDRADE; RODRIGUE; DOSCHER (2010)3.

Isto ocorre porque a hegemonia ou o poder do médico de narrar a surdez se vale de um status conferido a esse sujeito no decorrer da própria história da surdez. Sobre o status desse profissional, Foucault (1996, p.57) salienta que

\footnotetext{
3 Espaço de Aula - Sugestões de Aula do Portal do Professor. Sugestão de Aula: Deficiência auditiva - entendendo como se formam os sons e como os captamos. Disponível em: http://portaldoprofessor.mec.gov.br/ fichaTecnicaAula.html?aula=26594. Acesso em: 14 ago. 2019.
} 
[...] esse status dos médicos é, em geral, bastante singular em todas as formas de sociedade e de civilização: ele não é, quase nunca, um personagem indiferenciado ou intercambiável. [...] Sua existência como fala médica não é dissociável do personagem, definido por status, que tem o direito de articulá-lo, reivindicando para si o poder de conjurar o sofrimento e a morte.

Em contrapartida, é curioso constatar - tendo em vista a diversidade de agentes que discursam a respeito dos indivíduos surdos - o fato de que esses sujeitos se encontram quase sempre na posição de serem narrados pelos outros, o que faz com que, na maioria dos registros, a voz deles seja silenciada.

Esse silenciamento do surdo, ou a reduzida possibilidade de falar sobre suas vidas, está diretamente implicado com as próprias relações de poder que historicamente foram legitimando a autoridade de médicos, pais, professores e psicólogos de darem voz às pessoas com deficiência. Essa observação leva-nos a atentar para o que Tomazini (1998, p. 125) afirma sobre as interdições ao discurso.

Àqueles indivíduos marcados por uma distinção, efetivamente não é dada a palavra. Não lhes perguntamos o que querem ou não, o que precisam e o que realmente lhes interessa. Seu saber é desqualificado, considerado não competente ou insuficientemente elaborado: saber ingênuo, hierarquicamente inferior, abaixo do nível requerido de conhecimento e de cientificidade.

Tais considerações mostram-nos que, em uma determinada esfera discursiva, não circula um discurso de forma homogênea, mas há uma luta pelo poder de dizer. No caso do espaço formativo do portal em questão, percebemos que não há uma função unificante na produção da surdez; há, sim, uma luta que é embatida por agentes dos vários campos do saber (medicina, psicologia, educação, dentre outros) envolvidos nesse processo, em que se revela a diversidade de sujeitos com status diferenciados, advindos de posições sociais diversas, na disputa pela hegemonia de uma discursividade sobre a surdez. Essas diferentes maneiras de narrar a pessoa surda dependem do lugar político que o enunciador ocupa na sociedade, da teia de poder que atravessa a comunidade em que está inserido e da rede de saberes que a essa se vincula, o que faz surgir divergentes representações culturais desses sujeitos.

\section{A REPRESENTAÇÃo CULTURAL dA SURDEZ NO ESPAÇO FORMATIVO DOCENTE: LIMITAÇÃ̃o, MUDEZ E FALTA}

Inicialmente cabe salientar que os discursos sobre a surdez, no Portal do Professor do MEC, são constituídos ou atravessados por enunciados que reforçam a inclusão desses sujeitos. Vejamos, por exemplo, o fragmento abaixo, em que uma professora relata a experiência com alunas surdas na sala de aula regular, em sua prática pedagógica:

Formada em Pedagogia, há dois anos no magistério, Carmem conta que a experiência da inclusão tem sido muito positiva. "No início do ano, as duas estavam muito tristes, muito quietinhas, mas agora estão mais alegres e participativas". Quando querem se comunicar com a professora, elas mandam mensagens via celular. "É muito gratificante, diz" (JORNAL DO PROFESSOR, [2009]).

No entanto, é interessante sublinhar que, embora o discurso da professora seja atravessado pela noção da inclusão e pelos ideais de igualdade de oportunidades, baseia-se na ideia de que basta estar inserido em sala de aula regular para estar incluso. Essa prerrogativa desrespeita ou desconsidera a importância das condições mínimas para a aprendizagem dos alunos, nesse caso das alunas surdas.

Logo, por um gesto de interpretação, entendemos que, se fosse dado a essas alunas surdas o poder de narrar ou de falar por si mesmas, possivelmente elas não demonstrariam tanta "alegria" em apenas estar alocadas em uma sala de aula regular. Isto porque a necessidade de usar um celular como o único meio de comunicação com o educador usurpa um direito básico da pessoa surda, que consiste na garantia de um intérprete em sala de aula para assegurar as condições mínimas de aprendizagem e de comunicação entre aluno e professor.

A surdez - como falta ou como limitação - é uma das representações recorrentes que aparecem nos discursos encontrados no Portal e que podem ser ilustradas pelo próprio texto sugerido para debate em uma das aulas desse espaço formativo, cujo título é "Os surdos-mudos e suas limitações". Através desse enunciado, em um jogo de objetivação, ressalta-se a incapacidade das pessoas surdas de interagir com o mundo, devido às limitações decorrentes da perda da audição. Segue abaixo um excerto do texto em questão:
Os surdos-mudos e suas limitações
As pessoas surdo-mudas estão desprovidas de sua fala e de sua audição. Por esse motivo, a sua interação com o mundo está seriamente comprometida. Esse fato torna limitado o seu convívio social, tornando-as mais dependentes e dificultando-as de exercerem a sua cidadania (TEIXEIRA; FAGUNDES, 2010) ${ }^{4}$.

\footnotetext{
4 Trecho extraído do Espaço da Aula - Diferentes leituras para pessoas com necessidades especiais: Braille, Libras e leitura labial.
} 
Obviamente, não podemos desvincular a surdez da falta da audição, contudo afirmar que os surdos são limitados, que não conseguem interagir com o mundo social ou exercer a sua cidadania é um grande equívoco. Esse tipo de discurso tem como consequência a construção de significados que colocam os surdos em uma posição de subalternidade em relação à comunidade ouvinte. Sobre a representação da surdez como falta, Thoma (2002, p. 244) esclarece que

A leitura da surdez como falta está presente na história da surdez e dos surdos, contada a partir dos que ouvem: na literatura especializada, nos jornais, na televisão, no cinema, etc. Nomeando, narrando, descrevendo a alteridade surda a partir de um viés "faltante", os significados da normalidade mantêm e ampliam a fixação dos surdos como sujeitos inferiores aos que ouvem.

Associar a surdez à mudez ou ao silêncio é também uma das representações que aparecem nos discursos que integram esse espaço formativo. No entanto, é curioso constatar que tal representação foi encontrada justamente em uma aula cuja proposta é abordar as diferentes leituras para pessoas com deficiência (entre elas, o Braille, a Libras e a leitura labial). O excerto abaixo revela essa associação.

\section{O que o aluno poderá aprender com esta aula:}

Descobrir de quais maneiras as pessoas surdas e/ou mudas podem estabelecer uma interlocução social, através da utilização do sistema LIBRAS e da leitura labial (TEIXEIRA; FAGUNDES, 2010) ${ }^{5}$.

A associação da mudez à surdez é um grande equívoco, consequência, muitas vezes, do desconhecimento do que realmente significa a surdez. Sobre isso, Thoma (2002) salienta que nem no sentido biológico nem no antropológico-social os surdos podem ser considerados como mudos. Primeiramente porque não têm lesões nos órgãos fonadores e, segundo, porque falam, porém, em outra modalidade. Sobre a associação entre surdez e silêncio, a autora sublinha que, "enquanto para os ouvintes o silêncio é uma condição de isolamento ou uma recusa decorrente da falta do som, para os surdos/as o silêncio não é mais do que uma condição de existência como sujeitos visuais" (THOMA, 2002, p. 243).

Além disso, é preciso explicitar que, na análise dos artefatos culturais presentes no portal examinado, percebemos um total silenciamento das pessoas surdas, o que evidencia que a alteridade surda é narrada através

\footnotetext{
5 Trecho extraído do Espaço da Aula - Diferentes leituras para pessoas com necessidades especiais: Braille, Libras e leitura labial
}

da voz dos ouvintes. É intrigante reparar, nesse espaço formativo, que pessoas com diferentes deficiências se fizeram ouvir. No entanto, não houve a menor ocorrência de os surdos falarem por si mesmos. Cremos que esse silenciamento pode estar diretamente implicado com a representação cultural de que a surdez estaria relacionada também à mudez ou à incapacidade de se comunicar.

\section{DEFICIÊNCIA AUDITIVA OU SURDEZ? A Patologização do OUTRo}

Outro aspecto que nos chama atenção nos discursos do portal analisado é a utilização da terminologia "deficiente auditivo" para se fazer referência às pessoas surdas, como verificamos no excerto abaixo:

Conceituar o que é um som e os caminhos percorridos até ser reconhecimento pelo Sistema Nervoso Central (SNC);

Conceituar Deficiência Auditiva (DA): o que é, porque isso acontece e como tratar;

Abordar a inclusão escolar de uma pessoa com DA: sua importância social e educacional, recursos que podem ser utilizados, e o que fazer para participar ativamente deste processo (ANDRADE; RODRIGUE; DOSCHER, 2010).

Assim, o uso dessa terminologia reflete uma concepção da surdez centrada em uma perspectiva patológica e amparada em uma visão médico-organicista da deficiência. Behares (1993) critica o uso dessa expressão porque considera que nela o surdo é visto como portador de uma patologia localizada, de uma deficiência que precisa ser tratada para que seus efeitos sejam debelados.

Nesse contexto, Behares (1993) chama a atenção para a necessidade de se ver os surdos sob uma perspectiva sociocultural. Nessa visão, considera-se que o surdo difere do ouvinte não apenas porque não ouve, mas porque desenvolve potencialidades psicoculturais próprias. Para o autor, o uso da expressão surdo revela uma amplitude social que situa a perda auditiva como apenas um fator - restrito aos níveis médico e terapêutico. Desse modo, no contexto de vida da pessoa surda, esse fator clínico não ocuparia uma posição tão significativa para o seu desenvolvimento individual e grupal.

Evidentemente o emprego do termo "deficiente auditivo" se insere na prática da utilização de procedimentos que visam ajustar os surdos aos padrões linguísticos mais aceitos e valorizados na sociedade e que envolvem tratamentos e/ou atendimentos sistemáticos de fala oral ou de oralização. Consequentemente, acreditamos que a terminologia "deficiência auditiva", tão 
recorrente nos discursos midiáticos do portal, acaba, em alguma medida, reforçando os discursos históricos a respeito da surdez - discursos aficionados por uma visão médica ou patológica da deficiência. Em relação a essa questão, Skliar (2001, p. 105) esclarece que

[...] a ideologia dominante na educação e na escolarização dos surdos, no último século, parece estar sendo incomodada, desajustada e inclusive contestada, a partir de novos olhares sobre a surdez. Ela já não é pensada unicamente como deficiência, mas como uma questão epistemológica.

Outro aspecto a se ressaltar é que, embora as aulas tenham como objetivo refletir sobre a inclusão do aluno surdo na escola, a insistência em trazer apenas a discussão sobre a Língua Brasileira de Sinais (Libras) evidencia o quanto, para o professor, parece que o domínio dessa língua é suficiente para compreender o surdo e promover a inclusão. Dessa forma, ainda que reconheçamos a importância da Libras para a inclusão e para o desenvolvimento desses sujeitos, questionamos a representação da surdez apenas sob o aspecto linguístico, como se não houvesse mais nada além da língua, ou como se a surdez se limitasse apenas a esse aspecto.

$\mathrm{Na}$ análise dos artefatos culturais selecionados, fica evidente que o eixo central da discussão sobre a surdez localiza-se na ideia da Língua de Sinais, como vemos através dos recursos utilizados pelos próprios professores nas aulas sobre essa temática, como nas Figuras 1, 2, 3,4 e 5 .

Figura 1 - Vídeo "Os três porquinhos em Libras" veiculado no Espaço de Aula

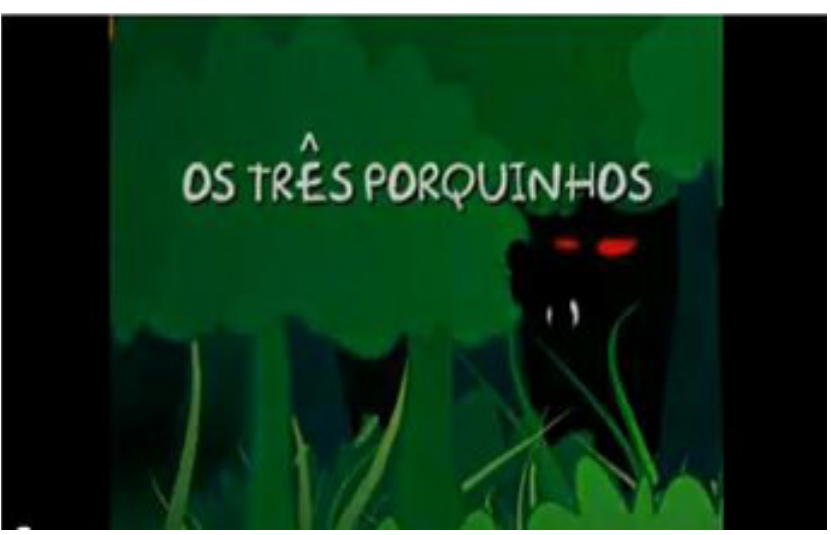

Fonte: Captura de imagem de https://www.youtube.com/watch?v=JdpN-Es1p5Y6.

\footnotetext{
6 Vídeo extraído do Espaço da Aula - Os Três Porquinhos (GUIMARÃES; DIAS; OLIVEIRA, 2014) - Recursos Complementares - Vídeo - A história dos Três Porquinhos em Libras
}

Figura 2 - Atividade de leitura do numeral em LIBRAS na aula "Aprendendo a se comunicar usando as mãos"

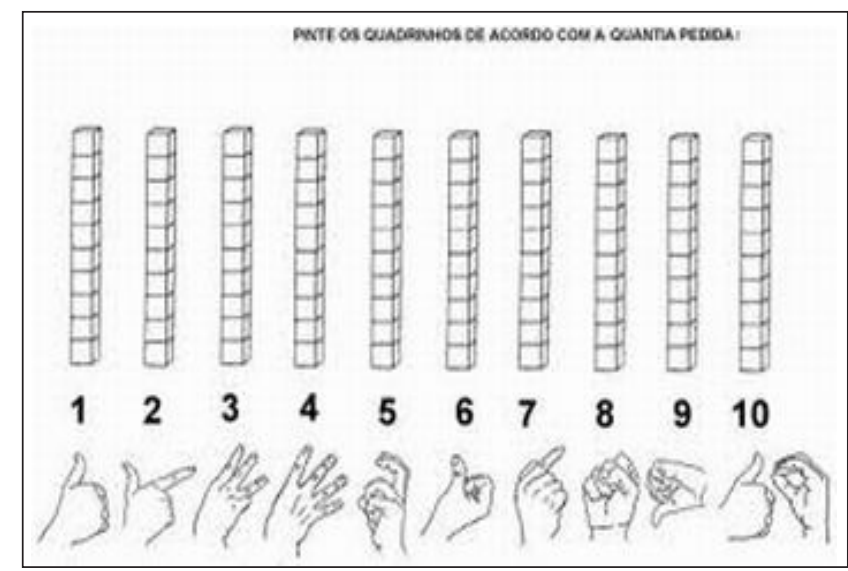

Fonte: Captura de imagem do Portal do Professor do $\mathrm{MEC}^{7}$

Figura 3 - Alfabeto em Libras - Imagem veiculada na aula "Deficiência Auditiva: entendendo como se formam os sons e como os captamos"

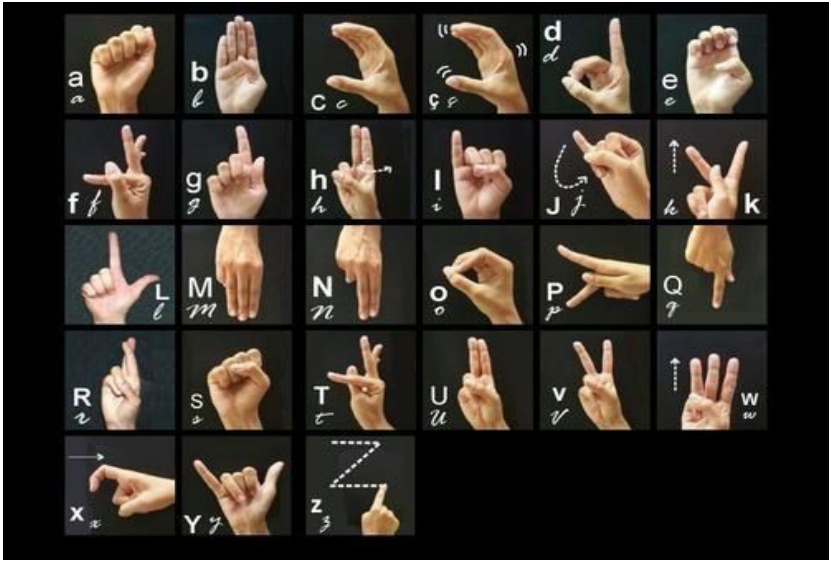

Fonte: Captura de imagem do Portal do Professor do $\mathrm{MEC}^{8}$

Figura 4 - Matéria “Aulas de Libras mudam comportamento de alunos ouvintes" veiculada no Jornal do Professor

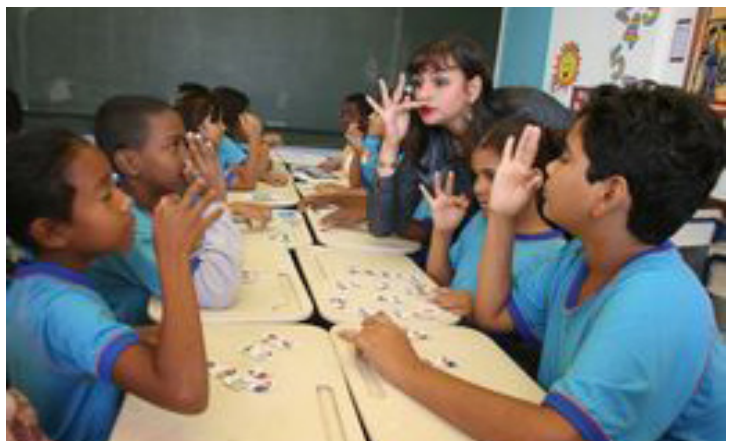

Fonte: Captura de imagem do Jornal do Portal do Professor do $\mathrm{MEC}^{9}$.

Extrato do 4을 momento da aula "Aprendendo a se comunicar usando as mãos" (SILVA; MEDEIROS, 2010).

8 Extrato da sugestão de atividade "Alfabeto em Libras" (ANDRADE; RODRIGUE; DOSCHER, 2010).

9 Extrato do Jornal, Edição 51 - Libras na Escola. 
Figura 5 - Matéria "Língua de Sinais ajuda escola a melhorar rendimento de estudantes" veiculada no Jornal do Professor

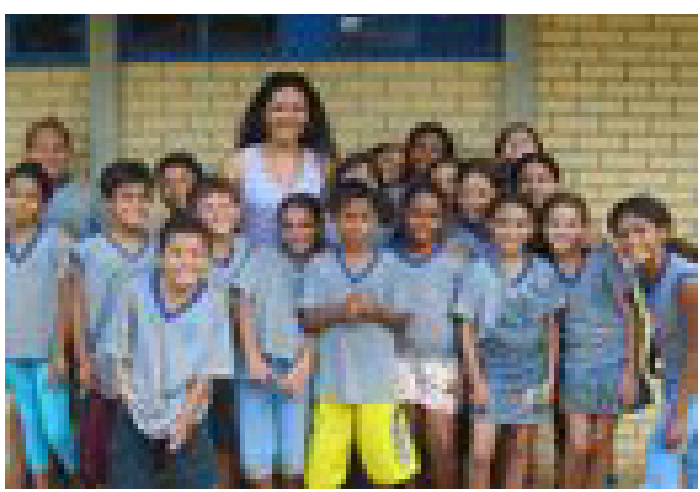

Fonte: Captura de imagem do Jornal do Portal do Professor do MEC ${ }^{10}$.

São dignas de atenção também as matérias veiculadas no Jornal do Professor, em uma edição intitulada " $\mathrm{O}$ ensino de Libras na escola". Nessa edição, mais uma vez, o único aspecto explorado é a Libras, o que reitera a preocupação com o ensino dessa língua nas instituições de ensino regular (Figuras 4 e 5 ).

Provavelmente o discurso que enfatiza a utilização da Língua Brasileira de Sinais está atrelado à repercussão social e política da proposta bilíngue na escola. No entanto, ao se ressaltar apenas o uso da Libras como condição necessária para a inclusão, deixa-se de lado ou se desconsidera outros aspectos tão importantes em relação à pessoa surda. Cabe, então, recorrermos a Skliar (2001, p.91) quando este afirma que

[...] se a tendência contemporânea é fugir - intencional e/ou ingenuamente - de todo debate que exceda o plano estrito das línguas, corre-se o risco de transformar a proposta bilíngue em mais um dispositivo pedagógico da educação especial, em mais uma grande narrativa educacional que conserva as mesmas representações sobre a surdez e os surdos; em síntese, a educação bilíngue pode se transformar numa "metodologia" positivista, não histórica e despolitizada.

Com base no exposto, vale questionar a proposta de formação de professores do portal, em que a educação das pessoas surdas é vista unicamente sob o enfoque do desenvolvimento de habilidades linguísticas em duas ou mais línguas. Conforme defende Skliar (2001, p.93),

Os múltiplos projetos chamados de educação bilíngue para surdos não têm que se contentar simplesmente em definir formalmente a utilização de duas línguas dentro da educação de surdos. A aceitação - como "tolerância" - da Língua de Sinais não supõe uma reconversão significativa dos problemas. Ainda

\footnotetext{
${ }^{10}$ Extrato do Jornal, Edição 51 - Libras na Escola.
}

existindo um espaço para as duas línguas em questão, cada uma pode perfeitamente corresponder a dois grupos diferentes e a duas representações antagônicas sobre o mundo. Desse modo, a educação dos surdos continuará sendo um projeto assimétrico de poderes e saberes.

Logo, a ênfase na utilização da Libras, no âmbito da discussão pedagógica sobre esse tema no portal investigado, faz com que sejam esquecidas questões como o papel social desempenhado pelas pessoas surdas; a luta da comunidade surda para ter os seus direitos reconhecidos; as relações assimétricas de poder entre a comunidade de surdos e a comunidade ouvinte; os movimentos de resistência dos surdos; entre tantos outros aspectos que poderiam ser explorados nesse espaço formativo disponibilizado pelo MEC.

Ao reconhecer as representações da pessoa surda como produtoras de cultura, é preciso considerar que a experiência visual dos surdos envolve vários tipos de significações comunitárias e culturais. Sobre isso, Perlin e Miranda (2003, p. 218) afirmam que:

\begin{abstract}
A experiência visual significa a utilização da visão (em substituição total à audição) como meio de comunicação. Dessa experiência visual surge a cultura surda representada pela língua de sinais, pelo modo diferente de ser, de se expressar e de conhecer o mundo, de entrar nas artes, no conhecimento científico e acadêmico. A cultura surda comporta a língua de sinais, a necessidade do intérprete, de tecnologia de leitura.
\end{abstract}

Outra questão que merece atenção é a forma como a Língua Brasileira de Sinais é apresentada nos artefatos que discursam a respeito da surdez. Evidenciou-se um conceito de Libras totalmente errôneo, uma vez que tal língua é apresentada como "linguagem" e os sinais utilizados para se comunicar são denominados de "gestos", como podemos verificar nos excertos abaixo:

Em seguida, o professor deverá pedir para que cada aluno fale para a classe, utilizando a Linguagem Brasileira de Sinais, o seu primeiro nome, como demonstra a figura 3 (Espaço da Aula - A deficiência auditiva na escola).

Vamos conhecer agora três maneiras de os surdosmudos se comunicarem: O MÉTODO LIBRAS - A sigla LIBRAS significa: Linguagem Brasileira de Sinais. É uma linguagem gestual codificada. Cada letra tem um gesto manual específico. (Espaço da Aula - Diferentes leituras para pessoas com necessidades especiais: Braille, Libras e leitura labial).

Esse conceito de Libras contraria as pesquisas científicas recentes, as quais revelam que a Língua de Sinais 
possui status linguístico. Os estudos de Quadros e Karnopp (2004) mostram que as propriedades das línguas de sinais são bastante semelhantes às das línguas orais, pois apresentam o mesmo tipo de princípios organizacionais e de parâmetros que formam a gramática das línguas. Além disso, existe na legislação a Lei no 10.436, datada de 24 de abril de 2002 (BRASIL, 2002), que regulamenta oficialmente a Língua Brasileira de Sinais, instituindo que

Art. 1 ํ É reconhecida como meio legal de comunicação e expressão a Língua Brasileira de Sinais - Libras - e outros recursos de expressão a ela associados.

Parágrafo único. Entende-se como Língua Brasileira de Sinais - Libras - a forma de comunicação e expressão em que o sistema linguístico de natureza visual-motora, com estrutura gramatical própria, constitui um sistema linguístico de transmissão de ideias e fatos oriundos de comunidades de pessoas surdas no Brasil (BRASIL, 2002).

Dessa forma, podemos afirmar que a representação da surdez, nos discursos do Portal do Professor do MEC, continua atrelada a uma concepção clínica da deficiência, reforçando uma série de mitos ouvintes sobre os surdos. Essa representação denota a ideia de que esses sujeitos possuem uma identidade fixa, estável, estática e permanente. Por meio da análise discursiva, constatamos que o surdo pode ser concebido através da conceituação da "deficiência auditiva" e ter sua inclusão garantida através do domínio e da oferta da "Língua Brasileira de Sinais (Libras)", o que resulta em uma leitura que produz o surdo a partir de uma visão deficitária ou superficial.

Poderíamos dizer, então, que, nos enunciados do referido espaço formativo, o surdo acaba sendo fixado a partir do referente maior ou do mais apreensível, que é "a falta da audição". É negada a esses sujeitos "colonizados", portanto, a possibilidade de serem pensados a partir de outras referências e de outros significados. Essa simplificação produz uma visão estereotipada a respeito deles, o que acaba impedindo uma reflexão a respeito do impacto das formas específicas de poder e de dominação que se exercem sobre os surdos.

\section{CONSIDERAÇÕES FINAIS}

Ao disponibilizar diferentes artefatos culturais pedagógicos, circunscrevendo direções e limites para a prática pedagógica do professor no que se refere à temática da surdez, os enunciadores do Portal denotam operar através de estereótipos. Nesse sentido, demonstram a presunção ou o anseio de deter um saber prévio sobre o Outro surdo. Esse saber é marcado por um discurso que está atento apenas às diferenças externas ou superficiais; um discurso que, ao invés de questionar as identidades cristalizadas, reafirma a imagem já estabelecida historicamente sobre aquilo que se conhece a respeito dos sujeitos surdos, pois reproduz as mesmas vozes que, há tempos e de forma hegemônica, vêm narrando e ocupando-se de objetivar a surdez.

Um problema observado foi o fato de que o Portal do Professor do MEC - ao dispor para os professores metodologias variadas, ao mostrar as condutas desejáveis, ao prescrever práticas pedagógicas que cumpram as metas educacionais propostas pelo Estado brasileiro para a educação das pessoas surdas em uma perspectiva inclusiva - pode acabar produzindo um efeito contrário, tendo em vista que muito do que é proposto nesse espaço formativo está atrelado a uma concepção de educação normalizadora e patologizante.

Essa maneira de representar culturalmente a surdez através de estereótipos pode trazer sérias implicações para a formação de professores, já que os discursos estereotipados produzem não só o aluno surdo, mas também, e sobretudo, os professores em formação, pois estes são interpelados por essa visão. Isso significa que os enunciados produzidos sobre a surdez no espaço formativo do portal não apenas nomeiam, simplificam e enquadram a deficiência, mas também regulam, coordenam e governam as ações dos professores, estruturando a sua forma de ver e de pensar a realidade e o Outro surdo.

É exatamente por isso que não podemos continuar (re)produzindo nas formações de professores - virtuais ou presenciais - conhecimentos sobre a surdez que encerrem ou aprisionem os sujeitos surdos nos discursos da estereotipia e dos essencialismos. Acreditamos que seja necessário produzir uma reflexão permanente a respeito das condições de produção do conhecimento sobre a surdez a fim de possibilitar aos alunos em formação a construção de um olhar crítico sobre os sentidos, as imagens e os enunciados que narram esses sujeitos, bem como uma constate problematização desses significados.

Por essa razão, é importante promover, nos processos formativos, um espaço discursivo para as pessoas surdas se expressarem, de modo que elas possam contar as suas próprias histórias. A criação desse espaço pode assegurar-lhes o direito de produzir contrarrepresentações que compliquem ou desestabilizem as certezas, que destruam as abstrações preconceituosas e estereotipadas e que mostre haver diferentes formas de ser "surdo". Em consonância com Costa (2005), acreditamos que devemos reivindicar o direito dos grupos e dos indivíduos excluídos de descreverem a si próprios, de falarem do lugar que ocupam e, sobretudo, de "inventarem as narrativas que os definem como participantes da história" (COSTA, 2005, p. 50). 
Podemos dizer, então, que, embora o portal analisado seja subsidiado pelo Ministério da Educação e detenha, portanto, legitimidade no seu poder de enunciação - por estabelecer acordos colaborativos com universidades públicas nacionais e internacionais -, o referido portal continua persistindo na produção da surdez de uma maneira pejorativa e estereotipada, o que faz com que o sujeito surdo, na sua multiplicidade e diferença, seja substituído por uma construção imaginária que, por vezes, não tem nenhuma relação com a realidade.

\section{REFERÊNCIAS}

ANDRADE, Maria Hilda Ruas; RODRIGUE, Paloma Alinnes Alves; DOSCHER, Andréa Leão. Deficiência Auditiva: entendendo como se formam os sons e como os captamos. In: Portal do Professor do MEC. Brasília: Ministério da Educação, 2010. Disponível em: http://portaldoprofessor.mec. gov.br/fichaTecnicaAula.html?aula=26594. Acesso em: 14 ago. 2019.

BEHARES, Luis E. Nuevas Corrientes en la Educación del Sordo: de los enfoques clínicos a los culturales". Cadernos de Educação Especial, Santa Maria, RS, n. 4, p. 20-52, 1993.

BHABHA, Homi K. O local da cultura. Belo Horizonte: UFMG, 1998.

BIELSCHOWSKY, Carlos Eduardo; PRATA, Carmem Lúcia. Portal do Professor do Brasil. Revista de Educación, Espanha, n. 352, p. 617-637, maio-ago. 2010. Disponível em: http://www.revistaeducacion.educacion.es/re352 experiencias.htm. Acesso em: 08 nov. 2016.

BRASIL. Lei no 10.436, de 24 de abril de 2002. Dispõe sobre a Língua Brasileira de Sinais - Libras - e dá outras providências. Disponível em: http://www.planalto.gov.br/ ccivil_03/leis/2002/110436.htm. Acesso em: 14 dez. 2012.

BRASIL. Ministério da Educação do Brasil. Portal Educacional do Professor do Brasil. In: Portal do Professor do MEC. Brasília: Ministério da Educação, [2008?]. Disponível em: http://portaldoprofessor.mec.gov.br/index. html. Acesso em: 14 dez. 2012.

CARVALHO, Rosita E. Temas em educação especial. Rio de Janeiro: WVA, 1998.

COSTA, Marisa V. Currículo e política cultural. In: COSTA, Marisa V. (org.). $O$ currículo nos limiares do contemporâneo. 4. ed. Rio de Janeiro: DP\&A, 2005. p.37-67.

ESPAÇO da aula. In: In: Portal do Professor do MEC. Brasília: Ministério da Educação, [2008?]. Disponível em: http://portaldoprofessor.mec.gov.br/espacoDaAula.html. Acesso em: 14 ago. 2019.

ESPECIAL Dia do Professor. Jornal do Professor, ed. 129, Brasília, DF, 14 out. 2016. Disponível em: http://portaldo professor.mec.gov.br/jornal.html. Acesso em: 14 ago. 2019.
FOUCAULT, Michel. Arqueologia do saber. Tradução de Luiz Felipe Baeta Neves. 7. ed. Rio de Janeiro: Forense Universitária, 2013.

FOUCAULT, Michel. Ordem do discurso. Tradução de Laura Fraga de Almeida Sampaio, ed. 16, São Paulo: Loyola, 1996.

GARCÍA, Carlos Marcelo. Formação de professores para uma mudança educativa. Lisboa: Porto Editora, 1999.

GUIMARÃES, Selma Sueli Santos; DIAS, Eliana; OLIVEIRA, Lazuíta Goretti. Os Três Porquinhos. Portal do Professor do MEC. Brasília: Ministério da Educação, 2014. Disponível em: http://portaldoprofessor.mec.gov. br/fichaTecnicaAula.html?pagina=espaco\%2Fvisualizar_ aula\&aula $=55393 \&$ secao $=$ espaco\&request_locale $=$ es. Acesso em 14 ago. 2019.

HALL, Stuart. The work of representation. In: HALL, Stuart. (org.). Representation: cultural representations and signifying practices. London: Thousand Oaks, 1997.

LIBRAS na escola. Jornal do Professor, Brasília, DF, ed. 51, Libras na Escola, 22 fev. 2011. Disponível em: http://portaldoprofessor.mec.gov.br/noticias.html?idEdicao= 54\&idCategoria=8. Acesso em: 14 ago. 2019.

MANTOAN, Maria Tereza. Inclusão escolar: O que é? Por quê? Como fazer? São Paulo: Moderna, 2005.

MARTINS, Lúcia A. A inclusão escolar do portador da síndrome de down: o que pensam os educadores? Natal: EDUFRN, 2003.

PERLIN, Gladis; MIRANDA, Wilson. Surdos: o narrar e a política. Ponto de Vista: Revista de Educação e Processos Inclusivos, n. 5, Florianópolis, 2003.

QUADROS, Ronice; KARNOPP, Lodenir B. Língua de sinais brasileira: estudos linguísticos. São Paulo: ARTMED, 2004.

SCHENINI, Fátima. PIAUÍ incentiva a inclusão em suas escolas. Jornal do Professor, [S. l.], e. 30: Acessibilidade e Inclusão, 26 nov. 2009. Disponível em: http://portaldo professor.mec.gov.br/conteudoJornal.html?request_locale= pt_BR\&pagina $=$ jornal\%2Fnoticia_interna\&pagina $=$ jornal $\% 2$ Fnoticia_interna\&secao $=\bar{j}$ ornal\&secao $=$ jornal $\&$ idConteudo=887. Acesso em: 14 ago. 2019.

SILVA, Edna Maria da; MEDEIROS, Suzana Maria Brito de. Aprendendo a se comunicar usando as mãos. In: Portal do Professor do MEC. Brasília: Ministério da Educação, 2010. Disponível em: http://portaldoprofessor.mec.gov.br/ fichaTecnicaAula.html?aula=24022. Acesso em: 14 ago. 2019.

SILVA, Érica Danielle. Movimentos identitários e políticas de inclusão na mídia: a (d)eficiência em tela. 2010. Dissertação (Mestrado em Letras) - Programa de PósGraduação em Letras da Universidade Estadual de Maringá, Maringá, 2010. 
SKLIAR, Carlos. Perspectivas políticas e pedagógicas da educação bilíngue para surdos. In: SILVA, S.; VIZIM, M. (org.). Educação especial: múltiplas leituras e diferentes significados. Campinas: Mercado das Letras, 2001.

TEIXEIRA, Josina Augusta Tavares; FAGUNDES, Andréa Vassallo. Diferentes leituras para pessoas com necessidades especiais: Braille, Libras e leitura labial. In: Portal do Professor do MEC. Brasília: Ministério da Educação, 2010. Disponível em: http://portaldoprofessor.mec.gov.br/

fichaTecnicaAula.html?aula=18686. Acesso em: 14 ago. 2019.

THOMA, Adriana S. O cinema e a flutuação das representações surdas: Que drama se desenrola neste filme? Depende da perspectiva. 2002. Tese (Doutorado em Educação) - Programa de Pós-graduação em Educação, Faculdade de Educação, Universidade Federal do Rio Grande do Sul, Porto Alegre, 2002.

TOMAZINI, Maria Elisabete A. Expatriação social e segregação institucional da diferença: reflexões. In: BIANCHETTI, L.; FREIRE, I. M. (org.). Um olhar sobre a diferença: interação, trabalho e cidadania. Campinas: Papirus, 1998. p. 111-133.

Recebido em: 6/3/2017.

Aprovado em: 21/11/2018.

Publicado em: 8/11/2019.

Endereço para correspondência:

Ana Flávia Teodoro de Mendonça Oliveira

Rua 235, 307 - Setor-Leste Universitário

74605-050, Goiânia, GO, Brasil

Clarissa Martins de Araújo

Centro de Educação

Av. da Arquitetura, s/n. - Cidade Universitária

50740-550, Recife, PE, Brasil

\section{Autoras:}

Ana Flávia Teodoro de Mendonça Oliveira

Doutora em Educação pela Universidade Federal de Pernambuco (UFPE).

Professora Adjunta da Faculdade de Educação (FE) da Universidade Federal de Goiás (UFG). Faculdade de Educação.

Orcid: https://orcid.org/0000-0002-4357-6558

E-mail: anaflavia teodoro@hotmail.com

Clarissa Martins de AraúJo

Doutora em Educação pela Université de Toulouse Jean Jaurès, França. Professora Associada IV do Departamento de Psicologia e Orientação Educacionais e do

Programa de Pós-Graduação em Educação, da Universidade Federal de Pernambuco. Membro do Grupo Formação de Professor e Profissionalização Docente DGP/CNPq e do Grupo de Estudos Formação de Professores e Práticas Inclusivas-GEFOPI. Orcid: https://orcid.org/0000-0002-4918-0175

E-mail: cmaraujo@ufpe.br 